\title{
INFÂNCIAS E CRIANÇAS: CONSUMO E CONSUMISMO SOB O PONTO DE VISTA DAS CRIANÇAS DO CEI PATO DONALD (MELEIRO - SC).
}

\section{CHILDHOODS AND CHILDREN: CONSUMPTION AND CONSUMERISM ON THE POINT OF VIEW OF CHILDREN FROM PATO DONALD EDUCATION CENTER (MELEIRO-SC)}

\author{
Liliane Maria Rodrigues Brito ${ }^{1}$ \\ Marli de Oliveira Costa ${ }^{2}$
}

\begin{abstract}
RESUMO: Este estudo aborda uma pesquisa realizada com seis crianças de cinco anos de idade, de uma escola pública do município de Meleiro/SC, acerca da moda e brinquedos infantis sob o olhar das crianças. Este artigo tem como objetivo compreender nas falas destas crianças a influência da mídia, refletindo também acerca do consumismo infantil. Para a concretização da pesquisa a metodologia utilizada foi o "Espaço de Narrativas". Para tanto, as crianças foram conduzidas para uma das salas da escola, espaço dedicado para fins pedagógicos. Nesse espaço foram realizadas algumas atividades pedagógicas que levaram as crianças a se expressarem e manifestarem os seus gostos e desejos. As referências que contribuíram para este artigo foram: quanto ao conceito de Infâncias e Crianças, DCN para a Ed. Infantil (2013), Ferreira (1993), Sarmento (2003; 2004), ECA (1990), Kuhlmann (1998); Quanto ao conceito moderno de infância Ariès (1978), Esperança (2013); Momento em que as crianças se tornam alvo do marketing, Sarmento (2004), Esperança (2013), Postman (1999); Quanto às reflexões sobre o consumo, consumismo e mídia, Esperança (2013), Sarmento (2000), Documentário "Criança, a alma do Negócio" (2007); Reflexão sobre a escuta gestos, expressões corporais e faciais das crianças, Rocha (2008), Leite (2008), Queiroz (2000), Francischini e Campos (2008). A pesquisa evidenciou que as escolhas das vestes e dos brinquedos que as crianças envolvidas na pesquisa apresentavam a influência da mídia.
\end{abstract}

PALAVRAS CHAVE: Infâncias. Crianças. Consumo. Marketing. Moda Infantil.

\section{ABSTRACT}

This study addresses a research carried out with six children of five years old, from a public school in the municipality of Meleiro / SC, about fashion and children's toys under the eyes of children. This article aims to understand in the speeches of these children the influence of the media, also reflecting on child consumerism. For the accomplishment of the research the methodology used was the "Space of Narratives". To do so, the children were taken to one of the school rooms, a space dedicated for pedagogical purposes. In this space some pedagogical

\footnotetext{
${ }^{1}$ Graduada em Pedagogia.moc@unesc.net

2 Doutora em Educação - Unesc, moc@ unesc.net

Saberes Pedagógicos, Criciúma, v. 1, n² , julho/dezembro 2017.- Curso de Pedagogia- UNESC
} 


\section{SABERES PEDAGÓGICOS}

Revista do Curso de Graduação de Pedagogia - Unesc

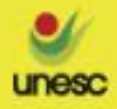

Unethes

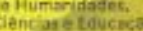

ediunesc

activities were carried out that led the children to express themselves and to express their tastes and desires. The references that contributed to this article were: regarding the concept of Infants and Children, DCN for Children's Ed (2013), Ferreira (1993), Sarmento (2003; 2004), ECA (1990), Kuhlmann (1998); As for the modern concept of childhood Ariès (1978), Esperança (2013); Moment in which children become the target of marketing, Sarmento (2004), Esperança (2013), Postman (1999); As for the reflections on consumption, consumerism and the media, Esperança (2013), Sarmento (2000), Documentary "Child, the soul of the Business" (2007); Reflection on listening to gestures, body and facial expressions of children, Rocha (2008), Leite (2008), Queiroz (2000), Francischini and Campos (2008). The research evidenced that the choices of robes and toys that the children involved in the research were influenced by the media.

KEYWORDS: Childhoods. Children. Consumption. Marketing. Kids Fashion.

\section{INTRODUÇÃO}

Este estudo apresenta as vozes das crianças de cinco anos de idade, que estudam em uma escola da rede pública do município de Meleiro/SC sobre suas escolhas acerca da moda infantil e dos brinquedos evidenciando preferências, gostos e desejos. Sabemos que na contemporaneidade as crianças tornaram-se alvos do apelo midiático para o consumo. Dentre os objetos e artefatos destinados as crianças encontra-se roupas, acessórios e brinquedos.

O tema desse artigo surgiu quando estudei as concepções de infância na Terceira fase do Curso de Pedagogia na disciplina de Teoria e Saberes da Infância e também por observar o que as crianças da escola em foco mais consomem, visto que atuo como professora dessa escola. O objetivo geral do estudo é compreender pelas vozes das crianças envolvidas na pesquisa, se seus gostos e desejos relacionados a moda e brinquedos têm influência da mídia. Sendo que o problema do estudo enuncia: Como as crianças do Centro de Educação InfantilCEI Pato Donald se relacionam com a moda infantil e seus brinquedos?

A metodologia utilizada para esta pesquisa foi "espaços de narrativas", no intuito de perceber as escolhas das crianças por meio de suas expressões e falas. A pesquisa de campo desenvolveu-se no CEI Pato Donald no município de Meleiro/SC com três meninos e três meninas.

Saberes Pedagógicos, Criciúma, v. 1, n², julho/dezembro 2017.- Curso de Pedagogia- UNESC 


\section{SABERES PEDAGÓGICOS}

Revista do Curso de Graduação de Pedagogia - Unesc

Os principais autores que contribuíram para as análises nesse estudo são: Sarmento (2003; 2004), Ariès (1978) e Esperança (2013). Para abordar o momento em que as crianças se tornam alvo do marketing Sarmento (2004), Esperança (2013), Postman (1999). Quanto às reflexões sobre o consumo, consumismo e mídia recorro novamente a Esperança (2013) e Sarmento (2000); No que se refere as Reflexões sobre a escuta, gestos, expressões corporais e faciais das crianças os autores e autoras Rocha (2008), Leite (2008), Queiroz (2000), Francischini e Campos (2008) .

Para abordar as falas das crianças sobre os objetos que consomem, em um primeiro momento discuto a construção do conceito moderno de infância e a diferença entre as categorias infância e criança. Na sequencia apresento algumas reflexões em torno do uso do marketing direcionado à infância e por último as vozes das crianças envolvidas na pesquisa e as relações dessas expressões com o incentivo ao consumismo na infância.

\section{CRIANÇAS E INFÂNCIAS: Uma abordagem histórica, social e cultural}

Para compreender as vozes das crianças do CEI Pato Donald em torno das escolhas das roupas e brinquedos que consomem é necessário revisitar, de forma geral, como a sociedade percebe as crianças atualmente e, como se deu a construção do conceito moderno de infância abordando as diferenças entre os conceitos de criança e infância.

\subsection{Infâncias e Crianças}

As Diretrizes Curriculares Nacionais para a Educação Infantil colocam que a criança é um sujeito histórico e de direitos que, nas interações, relações e práticas cotidianas que vivencia, constrói sua identidade pessoal e coletiva, brinca, imagina, fantasia, deseja, aprende, observa, questiona, experimenta, narra, produzindo cultura. (BRASIL, 2010, p. 12).

De acordo com o dicionário Aurélio (1993, p.153) da língua portuguesa, o termo criança quer dizer "ser humano de pouca idade", "ser humano na fase da infância, que vai do nascimento à puberdade". Para Kuhlmann e Fernandes (2004), infância é uma fase da vida construída historicamente, e criança diz respeito a realidade psicobiológica dos primeiros anos de vida.

Saberes Pedagógicos, Criciúma, v. 1, n², julho/dezembro 2017.- Curso de Pedagogia- UNESC 
Revista do Curso de Graduação de Pedagogia - Unesc

No entanto, por muito tempo as crianças foram vistas como seres meramente biológicos, ou seja, não existia para elas nenhuma ascensão social e tão pouco existencial. Para Sarmento (2004, p. 03) as crianças: “[...] pertenciam ao universo feminino, junto de quem permaneciam, até terem capacidade de trabalho, de participação na guerra ou de reprodução, isto é, até serem rapidamente integrados na adultez precoce."

No Brasil o Estatuto da Criança e do Adolescente - ECA, (Lei no 8.069, de 13/7/90) diz que a "criança é a pessoa até os 12 anos de idade incompletos [...]" (BRASIL, 1990, p. 1).

O pedagogo Moisés Kuhlmann Jr (1998), reflete sobre a categorização de criança de acordo com a idade biológica. O autor coloca que na "idade cronológica, como fato biológico", há várias limitações no que diz respeito aos mais diversos e variados momentos da vida, o que evidencia a categorização biológica não "ser elementos determinante suficiente para a sua definição" (KUHLMANN, 1998, p. 16), ou seja, para a definição do conceito de criança. Por isso, para o autor embora a palavra criança remeta à condição psicobiológica no período que vivem suas infâncias, tal condição acontece de acordo com a realidade onde as crianças estão inseridas e as relações sociais e culturais.

A sociedade está em constantes transformações sociais e culturais, sendo que vários saberes sobre as crianças foram sendo construídos. Saberes que remetem ao conhecimento e participação social das mesmas, ou seja, as crianças passaram a ser cuidadas por suas famílias, ingressaram nas escolas e recentemente estão sendo percebidas como sujeitos de direitos. Assim, ao contrário do termo criança, a infância não é uma fase biológica da vida. Infância é uma construção social e cultural, pois, é historicamente construída.

Em relação aos direitos das crianças, no Brasil, para o Estatuto da Criança e do Adolescente (Lei $\mathrm{n}^{\circ}$ 8.069, de 13/7/90) Art. 71, a criança e o adolescente têm direito a informação, cultura, lazer, esportes, diversões, espetáculos e produtos e serviços que respeitem sua condição peculiar de pessoa em desenvolvimento (BRASIL, 1990).

Compreendendo que as crianças participam da sociedade e de sua construção, é importante considerar que as mesmas trazem um conjunto de experiências vividas em contextos e lugares diferentes, já que

[...] as crianças participam das relações sociais, e este não é exclusivamente um processo psicológico, mas social, cultural, histórico..., buscam essa participação, apropriam-se de valores e comportamentos próprios de seu tempo e lugar, porque as

Saberes Pedagógicos, Criciúma, v. 1, n² , julho/dezembro 2017.- Curso de Pedagogia- UNESC 
Revista do Curso de Graduação de Pedagogia - Unesc

relações sociais são parte integrante de suas vidas, de seu desenvolvimento [...]. (KUHLMANN (1998, p. 31).

Assim conhecer as crianças e suas histórias, em diferentes modos e lugares é, considerar que as mesmas são construtoras da história da sociedade. Vários estudos, nos campos da sociologia, antropologia e outras áreas, asseguram que diante da participação e da construção das culturas da infância há uma ação concreta.

\subsection{A construção do conceito moderno de infância}

O conceito moderno de infância que temos hoje nem sempre existiu, crianças sempre existiram na história da humanidade, porém por séculos, as mesmas não faziam diferença na história e nem eram valorizadas no meio social e familiar.

Segundo Ariès, historiador francês, (1978, p. 156) "na sociedade medieval o sentimento da infância não existia", embora estas não fossem abandonadas e nem negligenciadas, isso significa que tinham a afeição da família ou parentes próximos, mas que o sentimento de infância correspondia à consciência ao apelo da "particularidade infantil". Ou seja, essas características "que distingue essencialmente a criança do adulto". Tais características não eram levadas em consideração e as crianças eram tratadas como adulto em miniatura.

Deste modo, as crianças participavam de todos os acontecimentos da vida dos adultos. "O sentimento de infância" foi marcado fortemente por dois grandes momentos, o primeiro é caracterizado pela 'paparicação', que surgiu no meio familiar, na companhia das criancinhas pequenas.” (ARIÈS, 1978, p. 163). E, o segundo foi a consciência da particularidade infantil, no que diz respeito a separação das crianças do mundo adulto.

Quanto a "Paparicação", Ariès, coloca que essa atitude levou algumas pessoas a terem reações adversas, e acusaram a "paparicação" como mera perda de tempo, ou seja, as crianças estavam sendo vistas como criaturas que despertavam nos adultos certo prazer pelas maneiras típicas de como elas se comportavam, assim era uma distração para os adultos. Ora, as crianças eram "[...] frágeis criaturas de Deus que era preciso ao mesmo tempo preservar e disciplinar.” (ARIÈS, 1978, p. 164) para que mais tarde se tornassem pessoas civilizadas.

Saberes Pedagógicos, Criciúma, v. 1, n², julho/dezembro 2017.- Curso de Pedagogia- UNESC 
Revista do Curso de Graduação de Pedagogia - Unesc

Ariès identifica que entre o fim do século XVI e inicio do século XVII formou-se outro sentimento da infância, agora as crianças "não se exprimia mais através da distração e da brincadeira." (ARIÈS, 1978, p. 162). Este segundo sentimento da infância caracteriza a tomada de consciência da inocência e da fraqueza da infância que proveio "dos eclesiásticos" e de "moralistas", que estavam "preocupados com disciplina e a racionalidade dos costumes". (ARIÈS, 1978, p. 163). Por meio destes dois momentos surge então o sentimento moderno da infância, ora, caracterizado pela paparicação, ora conduzidos por normas e regras que deveriam ser seguidas, tornando-as disciplinadas com o surgimento dos colégios.

Deste modo, a escola separou as crianças da vida dos adultos. "Uma nova noção moral deveria distinguir a criança, ao menos, a criança escolar, e separá-la: a noção da criança bem educada." (ARIÉS, 1978, p. 185), assim a “delimitação da infância” se põe em conexão com a invenção da escola moderna, surgia então o aluno-sujeito. (ESPERANÇA, 2013, p. 43). A tomada de consciência da particularidade infantil, juntamente com as transformações sociais que impeliram a industrialização levaram as crianças a tornarem-se, principalmente a partir do século XX, consumidoras em potencial.

\subsection{O momento em que as crianças se tornam alvo do marketing}

Por muito tempo as crianças eram vistas apenas por seres biológicos, ou seja, não havia nenhum espaço social para visibilizar a importância e o papel da criança enquanto sujeito histórico e social. "A ideia de infância é uma ideia moderna, deu-se início com o Renascimento, para se autonomizar, sendo caracterizada a partir do século das luzes [...]" (SARMENTO, 2004, p. 03).

Manuel Jacinto Sarmento, sociólogo português coloca que na contemporaneidade, as crianças passam a "contar na economia" da sociedade, participando "pelo lado da produção", sobretudo no "incremento do trabalho infantil, nos países periféricos e semiperiféricos" e pelo consumo. (SARMENTO, 2004). O consumo ocorre em função dos muitos produtos voltados para o público infantil. Para Sarmento o mercado entra de várias formas no cotidiano da criança,

Saberes Pedagógicos, Criciúma, v. 1, n², julho/dezembro 2017.- Curso de Pedagogia- UNESC 


\section{SABERES PEDAGÓGICOS}

Revista do Curso de Graduação de Pedagogia - Unesc

[...] entram pelo lado do marketing, com a utilização das crianças na promoção de produtos da moda ou na publicidade e ainda pelo lado do consumo, como segmento específico, extenso e incremencialmente importante de um mercado de produtos para a criança. (SARMENTO, 2004, p. 7).

Assim como Sarmento, Esperança (2013) percebe a crescente participação das crianças no mundo do consumo. A autora afirma que a sociedade transforma as crianças em "consumidoras mirins", em diversos lugares, tempos e espaços e, cada vez mais cedo.

Para o professor norte americano, Neil Postman (1999) com o surgimento dos meios de comunicação, as imagens que antes eram ocultas passaram a entrar e fazer parte da vida cotidiana das famílias e, respectivamente das crianças, tornando-a o principal alvo da publicidade infantil, aproximando-as do mundo dos adultos e posteriormente tornando-a crianças adultizadas. A oferta por meio de imagens veiculadas pela mídia torna público o que antes era privado, com este pensamento torna-se difícil proteger as crianças do mundo do marketing e do próprio consumo exagerado.

Postman (1999) coloca ainda que estudos anteriores mostram que antigamente o mercado se comunicava por meio da escrita com os adultos, as crianças não tinham esse acesso. Com a introdução da televisão, com mensagem de mídia audiovisuais, as crianças passaram a ter esse acesso, até porque as crianças não precisam de um preparo anterior para decodificar a mensagem, não é preciso por exemplo as crianças irem para a escola para aprender a assistir televisão, pois, "a sociedade na atualidade é marcada pela presença da mídia eletrônica, sobretudo da televisão, que tem homogeneizado informações e entretenimentos ao público, caracterizando um novo tempo.” (POSTMAN, 1999, p. 315).

O ambiente midiático fornece a adultos e crianças, ao mesmo tempo, as mesmas informações e, cada dia que passa, as crianças têm mais acessos as imagens televisivas. Todos os dias as crianças estão cercadas das mensagens do mercado, do consumo e, consequentemente do consumismo.

As empresas para se manterem no mercado precisam lucrar. E viram nas crianças um grande consumidor. (ESPERANÇA, 2013). Assim, com a utilização das crianças na produção de produtos da moda ou na publicidade, corpora-se no universo infantil uma oferenda ao marketing, pois boa parte do que é produzido pelo mercado é voltado para o consumo infantil como filmes, brinquedos, vestimentas, desenhos animados, adornos que seus personagens

Saberes Pedagógicos, Criciúma, v. 1, n², julho/dezembro 2017.- Curso de Pedagogia- UNESC 
Revista do Curso de Graduação de Pedagogia - Unesc

usam. (Sarmento, 2004). Neste sentido, o autor expressa que há uma "globalização da infância", as crianças ficam na mira do marketing, do consumismo, da propaganda e logo do lucro das empresas. Ainda para o autor: "este facto contribui poderosamente para a globalização da infância. Dir-se-ia mesmo que, aparentemente, há uma só infância no espaço mundial, com todas as crianças partilhando os mesmos gostos.” (SARMENTO, 2004, p. 9). Os produtos são expostos em vitrinas, oferecendo o que está na moda. Neste sentido, as crianças passaram a ser sujeitos agora expostos.

Para Esperança (2013) a cultura do consumo tem como "imperativo enfocar as próprias crianças como alvos do marketing”, buscando estabelecer um vínculo vicioso com a "marca" e com tudo o que é oferecido pelas empresas. Pois, como aponta Sarmento houve, “[...] a constituição do mercado de produtos culturais para a infância, tais como, programas vídeo, de televisão, cinema, desenhos animados, jogos informáticos [...].” (SARMENTO, 2004, p. 9). Assim, neste movimento do mercado mundial a difusão da oferta voltada para o público infantil, faz com que as crianças de todo o mundo compartilhem os mesmos padrões de moda e modelos de brinquedos.

Assim "as culturas da infância vivem do vai-vém das representações do mundo feitas pelas crianças", estas representações fazem um intercâmbio "com as representações 'adultas' dominantes", que Sarmento chama de "As duas culturas", uma que pertence ao universo infantil e a outra que pertence à sociedade. (SARMENTO, 2003, p. 04).

$\mathrm{O}$ autor ainda ressalta que "é no vai-vém entre culturas geradas, conduzidas e dirigidas pelos adultos para as crianças e culturas construídas nas interações entre as crianças que se constituem os mundos culturais da infância." (SARMENTO, 2003, p. 5). No entanto, as formas culturais produzidas para as crianças dirigidas pelos adultos requerem um conjunto de considerações, pois, na cultura infantil há um incentivo grande por parte do mercado, ou seja, há uma configuração da "indústria cultural da infância." (SARMENTO, 2003, p. 5) quando diz respeito à produção e promoção de brinquedos, vestimentas, materiais escolares para o mundo infantil.

O mercado oferece então para o universo infantil produtos que elas consomem, mediados pelo mundo da mídia, incrementadas na cultura e nos interesses dos adultos que gerenciam tal mercado. Deste modo, as crianças tornam-se visivelmente expostas a

Saberes Pedagógicos, Criciúma, v. 1, n², julho/dezembro 2017.- Curso de Pedagogia- UNESC 


\section{SABERES PEDAGÓGICOS}

Revista do Curso de Graduação de Pedagogia - Unesc

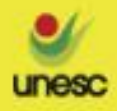

Unehos Acrodonica

ediunesc

propagandas de roupas, calçados de determinadas marcas, e até mesmo dos programas infantis, assim "as crianças são representadas como adultos em miniatura." (POSTMAN, 1999), pois as crianças reproduzem o mundo dos adultos e seus comportamentos.

\section{$2.4 O$ consumismo na história da infância}

Ao analisar as transformações na sociedade vê-se que, o que antes era restrito ao mundo das crianças, hoje se torna público. Deste modo, no mundo do mercado percebe-se que "a participação das crianças na esfera do consumo não é postergada para o futuro, mas se estabelece e se intensifica no tempo presente, vivido de forma acelerada e fugaz." (ESPERANÇA, 2013, p. 55), fazendo com que as crianças sejam consumidoras cada vez mais cedo. A relação entre criança e mercado, tem se manifestado como uma relação que inculca desejos, isso inclui filmes, programas infantis, desenhos animados, jogos, músicas, etc... aqui existe uma vasta "existência de formas culturais produzidas pelos adultos e destinadas ao consumo de crianças..." esta forma de consumo "constitui uma das mais impressivas componentes do mercado global de produtos para a infância.” (SARMENTO, 2000, p. 06).

De acordo com o documentário "Criança, a Alma do Negócio" (2007), "a publicidade é feita para encantar o consumidor", pois como já foi mencionado, uma das participações da criança na economia, se dá pelo consumismo. Percebe-se as estratégias do mercado convencendo as crianças por meio de imagens coloridas, divertidas do mesmo jeito como são vistas na televisão e, com os seus personagens preferidos, os objetos desejados tornam-se realidade palpável.

Compreendendo a história da programação específica para o público infantil na televisão, percebe-se que foi por volta de 1980 que surgiram os programas voltados para, as crianças. A partir deste momento os setores de "vendas destinadas às crianças, promovendo produtos licenciados com a marca e os nomes de apresentadores" (ESPERANÇA, 2013, p.56 apud ROSSI, 2007) cresceram rapidamente no mercado tornando-se uma realidade cada vez maior entre as crianças. De acordo com o documentário "Criança, a Alma do Negócio", podese dizer que hoje o grande objeto da casa é a televisão, ela está presente praticamente em quase todos os lares, a mídia com suas propagandas conversam o tempo todo com o seu

Saberes Pedagógicos, Criciúma, v. 1, n², julho/dezembro 2017.- Curso de Pedagogia- UNESC 
Revista do Curso de Graduação de Pedagogia - Unesc

público alvo, por isso que bastam apenas 30 segundos para uma marca influenciar uma criança (CRIANÇA..., 2007).

Assim, o deslocamento nas relações familiares que permitiu que a televisão se tornasse o centro nas famílias significou o incremento e a expansão do mercado de produtos infantis, a cada instante, a televisão "promove "novas demandas de consumo orientadas pelo imperativo da satisfação imediata." (ESPERANÇA, 2013 p. 56), influenciando desse modo, em demasia os desejos das crianças".

Nota-se que a grande expansão de mídias como o videogame, celular, tablets, televisão entre outros, são "elementos centrais na comercialização, "globalizando" a cultura infantil, porém estes "meios tecnológicos de informação, comunicação e entretenimento levam ao crescimento de apelos e demandas de consumo voltadas para as crianças consumidoras." (ESPERANÇA, 2013, p. 57). O documentário “Criança, a Alma do Negócio” afirma que é pelo consumismo que as pessoas se tornam igual umas as outras, é tudo muito padronizado, é tudo muito globalizado, é o mundo de hoje. (CRIANÇA, 2007).

Outra questão importante a ser mencionada é que as crianças que ficam expostas a determinados programas televisivos e são sensualizadas muito cedo. Pois entram em cena os adornos, como a sandália de salto, a unha pintada, o uso de baton, o uso de maquiagem, todos estes quites para o público infantil nivelam uma criança aprisionada em desejos imediatos, que os aproximam do mundo dos adultos.

O mercado vende o produto ligado a "marca" porque sabe que toda criança quer ser como seu personagem favorito que ele assiste na televisão. No entanto, é importante lembrar que os pais, a sociedade e o Estado são os responsáveis pelo desenvolvimento e integridade das crianças, o Estatuto da Criança e do Adolescente no art. $4^{\circ}$ aborda que "é dever da família, da comunidade, da sociedade em geral e do poder público assegurar, com absoluta prioridade, a efetivação dos direitos referentes à vida [...].” (BRASIL, 1990, p. 19).

Em tempos de leis que procuram garantir os direitos das crianças e que, no entanto, as mesmas são as maiores vítimas da propaganda mercadológica, vários estudos nas áreas da antropologia, educação e sociologia têm proposto ouvir o que as crianças pensam sobre seu "mundo de vida". 


\section{SABERES PEDAGÓGICOS}

Revista do Curso de Graduação de Pedagogia - Unesc

\section{ESCUTAR CRIANÇAS: É ESTABELECER RELAÇÕES}

Estudos recentes mostram que as crianças e suas infâncias tornaram-se objetos de pesquisas $^{3}$. Acredita-se na criança como sujeito social e construtora de culturas. Por meio de suas falas é possível entender melhor o papel social da criança enquanto sujeito ativo.

A criança fala por meio de gestos corporais, comportamentos, expressões, mas, muitas vezes na infância estes aspectos ficam nivelados, por isso suas múltiplas linguagens caracterizam o que elas têm dentro de si, deste modo "quando o outro é uma criança, a linguagem oral não é central nem única [...]," (ROCHA, 2008, p. 45). Portanto, para obter uma compreensão significativa do que pretendi alcançar, nesse estudo, procurei ter cuidado e atenção às diferentes linguagens que aparecem nas narrativas das crianças.

Escutar crianças é oferecer a elas uma relação de proximidade, como coloca o musioterapeuta Gregório José Pereira de Queiroz (2000, p. 31) “é estabelecer relação com o que escutamos atribuindo significado nos diversos diálogos culturais e, intercultural”. Para tanto, precisa-se incluir uma relação especial com elas, este mesmo autor afirma ainda que “esta relação está nos fatos que apontam para a importância da afinidade que estabelecemos com nossos sentidos, por isso que ela não apenas completa a ação dos sentidos ou lhes dá a qualidade de refinamento, mas também lhes dá significado". (QUEIROZ, 2000, p. 31).

A pesquisa com a criança possibilita realizarmos experiências sociais para assim entendermos que as mesmas são "agentes sociais.” (ROCHA, 2008, p. 46). Assim prevalece a ideia de que as relações sociais não são transmitidas, mas ao contrário são transformadas pela ação humana, sabemos que os indivíduos constroem duas histórias que juntas formam a cultura humana, uma é a história coletiva (social) construção da sociedade, a outra é a sua própria história (pessoal), juntas os humanos constroem o mundo.

Os autores citados anteriormente colocam que com relação às narrativas, o processo de investigação, a produção da criança pesquisada e a interpretação requerem de pesquisadores um olhar atento às várias manifestações da criança para facilitar a analise de dados.

A pesquisadora Rosângela Francischini e a pedagoga Maria Malta Campos (2008, p. 113) advertem que enquanto procedimentos de pesquisa, [...] "essas expressões são

\footnotetext{
${ }^{3}$ Como o livro: CRUZ, Silvia Helena Vieira (org). A criança fala: a escuta de crianças em pesquisas. São Paulo: Cortez, 2008.

Saberes Pedagógicos, Criciúma, v. 1, n², julho/dezembro 2017.- Curso de Pedagogia- UNESC
} 


\section{SABERES PEDAGÓGICOS}

Revista do Curso de Graduação de Pedagogia - Unesc

oportunidades que as crianças têm de expressar sentimentos, ideias, experiências de vida e constituem vias de acesso do pesquisador até eles". Pois, apresentar as especificidades das crianças na infância é compreender que elas são sujeitos sociais embora frágeis e pertencentes a sociedade autocêntrica, visto que as crianças que mais sofrem neste meio, são as de classe pobre “e, não são poucas as desigualdades de toda a ordem que atingem as crianças mais pobres do mundo." (DELGADO; MULLER 2008, p. 142).

É possível caracterizar as culturas infantis por meio das relações culturais da sociedade, a mídia, família, escola, marketing, as tecnologias, livros etc. Ou seja, uma sociedade geradora e conduzida por adultos, tornam as crianças adultos em miniatura, eis o significado da sociedade autocêntrica tudo gira em torno dos interesses dos adultos. No entanto, nos estudos atuais, a vida das crianças passou a ser tratada com um olhar mais refinado, no que diz respeito às infâncias repensou-se o seu lugar na sociedade, com esta iniciativa foram tomadas várias medidas em torno da criança. Por isso que conhecer as crianças, nos supõe conhecer a infância, a sua história, sob a luz das condições estruturais. Sarmento (2000, p. 16) aponta que,

Conhecer as crianças impõe, por suposto, conhecer a infância. Isto vale por dizer que os itinerários individuais, privados e singulares de cada criança só fazem completo sentido se perspectivados à luz das condições estruturais que constrangem e condicionam cada existência humana.

As crianças vivem em contextos diferentes, culturas diferentes, por isso a importância do termo infâncias, pois são vivenciadas em diferentes lugares e espaços. "[...] sempre houve várias infâncias, distintas entre si por condição social, por idade, por sexo, pelo lugar onde a criança vivia, pela cultura, pela época, pelas relações com os adultos." (ESPERANÇA, 2013, p. 46 apud MÜLLER, 2007, p. 96) deste modo percebe-se que a infância não tem lugar nem espaços próprios, as vivências são condicionadas conforme o contexto social e cultural de cada criança. Neste sentido todos os indivíduos foram crianças, mas nem todos tiveram infância.

Como professora da Educação Infantil tenho observado o quanto crianças em idade bem precoce, entre quatro e cinco anos, aparecem na escola com objetos e roupas construídas pelo mundo contemporânea para atender o público infantil. Assim a partir dos

Saberes Pedagógicos, Criciúma, v. 1, n², julho/dezembro 2017.- Curso de Pedagogia- UNESC 


\section{SABERES PEDAGÓGICOS}

Revista do Curso de Graduação de Pedagogia - Unesc

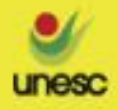

Unetsade Acadynica

unesc

to Humaridates.

ediunesc

suportes teóricos que me possibilitaram compreender que infância e que criança chegam até as escolas de Educação Infantil nos dias de hoje, realizei a investigação que apresento nesse momento, buscando compreender as escolhas das crianças em termos de moda e brinquedos, a partir de suas falas.

\section{MODA INFANTIL: SOB O OLHAR DAS CRIANÇAS}

Partindo do entendimento que as crianças são capazes de refletir acerca do mundo que as rodeia, busquei junto às crianças, perceber como elas percebem a moda e os brinquedos e qual a sua relação referente às ofertas veiculadas principalmente pela mídia. No entanto, a visão da criança não pode ser identificada apenas na linguagem oral, mas nas várias linguagens, por isso a fala "não é central nem única." (ROCHA, 2008, p. 45), no entanto é sempre acompanhada por gestos, expressões faciais. Por isso a concretização desta pesquisa buscou usar caráter lúdico, descritivo e exploratório.

A metodologia utilizada foi "Espaços de Narrativas". Espaços que possibilitam maior interação na "criação de sentidos, espaços de trocas e produção de conhecimento [...]", (LEITE, 2008, p. 130) a criança é compreendida como sujeito social, que tem voz e que contribui nas transformações da sociedade.

A pesquisa foi realizada em uma Instituição pública de Educação Infantil do Município de Meleiro e buscou estabelecer uma relação de confiança entre a pesquisadora e as crianças. As crianças participantes foram os próprios alunos e alunas da sala da pesquisadora. Ao todo foram seis crianças com idade de cinco anos.

Em um primeiro momento foram escolhidas quem participaria do estudo. Como todas as crianças da sala queriam participar, foi realizada uma votação, na qual deveria sair o nome de seis crianças, três meninos e três meninas. A votação ocorreu da seguinte forma: foi distribuído para todas as crianças da sala um pedaço de papel ofício branco, solicitei que cada um escrevesse seu primeiro nome no papel. Ao término as meninas depositaram numa caixa os seus respectivos nomes, logo em seguida os meninos fizeram o mesmo, ambos depositaram em caixas diferentes. Os papeis foram sacudidos, com a intenção de misturar os seus nomes que estavam dentro da caixa. Essa separação nas caixas diferentes foi necessária para poder obter o número igual entre meninos e meninas.

Saberes Pedagógicos, Criciúma, v. 1, n², julho/dezembro 2017.- Curso de Pedagogia- UNESC 
Para representar as meninas e os meninos e, não haver desavenças entre eles foi solicitado à frente uma menina e um menino cujo nome começasse com a primeira letra do alfabeto. As duas crianças retiraram das caixas o nome de três meninas e três meninos, na retirada dos papéis iriam lendo o nome dos participantes da pesquisa, logo após a leitura a votação se deu por encerrada. O grupo das seis crianças, três meninos e três meninas estavam completos, todos residentes em Meleiro, mas em bairros distintos. Para as crianças essa atividade representou um jogo e os que não foram selecionados não ficaram, aparentemente sentindo-se excluídos.

No segundo momento, as seis crianças levaram o termo de consentimento para ser assinado pelos pais. E trouxeram assinados. Assim, iniciamos os trabalhos investigativos.

\subsection{Os encontros pedagógicos}

A metodologia Espaço de Narrativa prevê a realização da pesquisa em um espaço diferenciado da sala de aula. Para Leite (2008, p. 136),

\footnotetext{
Se estamos numa instituição como a escola, organizamos os espaços de narrativa nos recreios, intervalos ou espaços livres, nunca numa turma, em horário de obrigatoriedade de aulas. Participar dos encontros passa primeiramente por querer dizer algo, querer expressar-se e ser ouvido.
}

Então levei as crianças para uma das salas, espaço dedicado para o apoio pedagógico da escola. Os pais as levavam no turno extraclasse. Os encontros foram organizados em quatro grandes momentos. Nos dois primeiros encontros foram especificados os motivos da pesquisa e, nos dois últimos encontros foram realizadas atividades em que as crianças puderam se expressar.

No primeiro encontro separei meninos e meninas. O objetivo da separação foi para perceber se tanto as meninas quanto os meninos tinham o mesmo gosto por personagens divulgados pela mídia. Nesse encontro também escolheram seus nomes fictícios para serem identificados, como forma de preservar suas identidades, pois "expor seus nomes significa expô-las a qualquer tipo de risco.”(LEITE, 2008, p. 138),) Para preservá-las, as crianças escolheram os nomes de acordo com o seu personagem preferido, por isso que "optamos que 
elas escolham apelidos pelos quais querem ser chamadas", pois "na medida em que são elas mesmas que escolhem seus apelidos, elas se reconhecem e se identificam com ele." (ESPERANÇA, 2013, p. 137). Assim, os personagens convidados a fazer parte desta aventura foram: Pikachu, Macuin, Princesa Sofia, Elza, Flutterbye e Ben 10. Logo na escolha desses nomes percebe-se a influência da mídia de imediato.

O primeiro encontro aconteceu com as três meninas, no tapete da sala encontravam-se espalhadas várias figuras, imagens de personagens elementos que povoam o universo infantil, veiculados ou não pela mídia, em vestimentas, calçados, adornos, materiais escolares e brinquedos. Em roda de conversa as meninas manipularam as figuras, conversando de várias maneiras sobre o que estavam vendo. O segundo encontro ocorreu com os meninos na mesma sala, e o procedimento foi o mesmo das meninas.

No terceiro encontro na mesma sala foram reunidas as seis crianças participantes, na sala tinham as mesmas figuras. Os seis juntos observaram e manipularam as mesmas, conversaram entre eles. Logo em seguida, foi solicitado que desenhasse numa folha de papel ofício o desenho que eles mais gostavam de assistir na TV, e assim foi feito. A atividade proposta foi estabelecida a partir do diálogo das crianças sobre o que estavam vendo.

O quarto encontro aconteceu num lugar fora da escola, por ser lugar atraente para as crianças. Com o apoio dos pais, as crianças foram conduzidas a dois pontos comerciais na cidade. Esta atividade teve por finalidade identificar se as ofertas, as propagandas, o marketing, fazem efeito imediato sobre as crianças, se influenciariam o querer comprar das crianças no local exato de compras.

\subsection{As falas e expressões das crianças}

As duas primeiras atividades tiveram como objetivo analisar o comportamento das crianças para compreender seus gostos e suas preferências. Ao verem e manipularem as imagens impressas de acessórios infantis veiculados pela mídia, as meninas demonstraram muita alegria e, com ar de surpresa disseram que queriam levar tudo aquilo para casa. No entanto, indagadas sobre o porquê gostariam de levar para casa elas disseram:

Princesa Sofia: - "Eu vou dizer pra minha mãe: compra mãe! Compra tudo isso!!”. 
Revista do Curso de Graduação de Pedagogia - Unesc

Este pensamento se aproxima das reflexões de Esperança (2013), quando compara as crianças contemporâneas como 'nascidas para comprar'."Essa condição que possibilitou a intensificação de vínculos entre as crianças e o que elas veem foi com a expansão dos meios de comunicação." (ESPERANÇA, 2013 p. 56), sobretudo a televisão que se embrenhou com suas propagandas, sendo que as mesmas são feitas para encantar as crianças fazendo com que acreditem que aquele é seu universo.

Elza também manifestou outros desejos como ficou explícito em sua fala: - "Eu já pedi duas coisas pra minha mãe no dia do meu aniversário, a boneca do Cúmplice o resgate por amor e a boneca "Baby Alive", (expressou cantando a música com a qual a telenovela inicia)".

As crianças iniciam suas vidas rodeadas de oportunidades de consumo, são

gerações atuais que se tornaram alvos privilegiados do marketing e da propaganda, relevância assumida pelas mídias eletrônicas no cotidiano das crianças implicando o estabelecimento de vínculos estreitos entre formas de consumo simbólico e material, promovendo, assim, uma potente associação entre o entretenimento e o comércio. (ESPERANÇA, 2013 p. 95).

Quando perguntei sobre como estavam se sentindo afirmaram: Flutterbye: - "Eu sinto que eu gostaria de ganhar todos, eu peço mãe tu precisa fazer compras!".

$\mathrm{Na}$ atividade proposta do desenho, à medida que as crianças desenhavam intervia dialogando com elas. Esta estratégia também possibilitou conhecer um pouco mais dos desenhos e programas infantis de TV preferidos pelas crianças. Nos desenhos feitos pelas crianças apareceram dois programas de televisão favoritos. Uma das crianças relatou que assiste mais a telenovela Chiquititas ${ }^{4}$ e os desenhos de Were kits. Elza porém mencionou outro programa: - "Quando eu crescer eu quero ser cantora igual Cúmplice de um Resgate pra mim ficar famosa (risos)".

Diante das falas das meninas foi possível perceber que elas conhecem o que estão falando e, como reproduções midiáticas de riqueza, celebridade e sucesso entrelaçam com as expectativas e desejos de ser das crianças participantes da pesquisa. Com a fala acima fica explícito que as crianças são constantemente influenciadas pela mídia, em uma linguagem 
Revista do Curso de Graduação de Pedagogia - Unesc

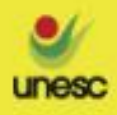

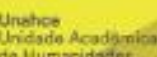

subliminar usada pelo capitalismo. Esperança (2013, p. 55) aponta que "as crianças assumem uma posição estratégica como consumidores atuais e futuros, que nasceram e vivem imersos num ambiente social em que as demandas de consumo se renovam de forma incessante e contínua", estes pequenos consumidores já são contados como aqueles que influenciam nas “decisões de compras dos adultos" (ESPERANÇA, 20013, p. 56). Como se pode ver acima da afirmação na fala das meninas Elza, Flutterbye, Princesa Sofia.

Com relação aos meninos o procedimento foi o mesmo, com gestos faciais deixaram transparecer suas alegrias. Porém quando viram os personagens de meninas exclamaram: - "Coisas de meninas não”!! (braços cruzados). Mas ao verem os super heróis estampados em roupas, brinquedos, calçados e em alguns materiais escolares, a alegria ficou também estampada em seus rostos, demonstrando grande afeição pelo o que estavam vendo.

Observando a empolgação das crianças questionei sobre o que eles gostam no Ben 10, neste diálogo Pikachu exclamou: - "Nossa que bonito, eu gosto do Ben 10, eu tinha um relógio dele, mais ele (o relógio) estragou, aí a minha mãe comprou outro, não do Ben 10, do homem de ferro."

Bem 10 listou o que tinha em casa: - "Esse eu tenho, esse eu tenho"...

- "Hum! Eu gosto deles (homem aranha, homem formiga, tour, super homem, homem de ferro...), é bom isso! Parece que a gente tá lá com eles" [com os heróis].

No local de compras ao ver o seu brinquedo preferido, Macuin com um sorriso no rosto exclamou: - "Esse aqui é um carro que vira robô... gostei tanto desse!".

A fala dos meninos remete que “as 'crianças do consumo'. Isso é, as gerações atuais, iniciam suas vidas como alvos privilegiados do marketing e da propaganda, fazendo da criança um alvo comercial específico" (ESPERANÇA, 2013, p. 95), aqui fica explícito o que as crianças mais consomem, com o que mais interagem especificamente na TV. Toda esta demanda de mercado explica o porquê as crianças se tornaram o principal alvo da publicidade, são objetos produzidos para elas mesmas.

$\mathrm{O}$ terceiro e o quarto encontro aconteceram com as seis crianças juntas, tanto as meninas quanto os meninos disseram que estavam muito felizes em ver todos aqueles brinquedos, calçados e roupas, pesquisando sobre a relação que elas têm com a moda pude

\footnotetext{
${ }^{4}$ Chiquititas é uma telenovela infanto-juvenil brasileira produzida pelo Sistema Brasileiro de Televisão (SBT) e Saberes Pedagógicos, Criciúma, v. 1, n², julho/dezembro 2017.- Curso de Pedagogia- UNESC
} 


\section{SABERES PEDAGÓGICOS}

Revista do Curso de Graduação de Pedagogia - Unesc

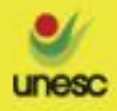

Unetses acadonico

unesc

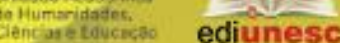

constatar que suas maiores preferências eram roupas e brinquedos tanto para as meninas quanto para os meninos. No entanto, "estes brinquedos que surgem no mercado, estereotipados e em massa, condicionam as brincadeiras que com eles se têm e uniformizamnas." (SARMENTO, 2004, p. 15).

Diante de suas modas preferidas estavam aquelas que estão atualmente na TV, como por exemplo, a novela "Cúmplices de um Resgate" ${ }^{5}$ as crianças querem ser aquilo que passa na TV, por isso que o consumo imprime na criança uma crença que ter isso ou aquilo é ser rico como podemos perceber na fala da Elza: - "Parece que estou rica quando a minha mãe compra coisas pra mim!”.

No entanto, esta reprodução ao consumismo estabelece modos de como ser e de como viver, "moldando escolhas e condutas individuais." (ESPERANÇA, 2013, p. 95). Nas referidas atividades foi possível verificar para esta pesquisa que todos os aspectos que foram abordados sobre moda infantil, das vestes aos materiais escolares há um grande ponto atribuído à influência, dos programas infantis, da televisão, de jogos e, outros meios midiáticos.

Ao entrar na loja percebi o tamanho do entusiasmo das crianças, todos olhando para as estantes e, logo correram para os corredores mais coloridos da loja - espaços dedicados à criança, com brinquedos, ao lado de materiais escolares, logo adiante calçados, foi então que uma das crianças expressou: - de "tanta coisa... eu gostaria de passear em todos os shoppings". Aproveitei esta fala e lhe perguntei o porquê deste desejo, e obtive a seguinte resposta de Flutterbye: - "Eu gostaria de passear no shopping de Araranguá, no shopping de Criciúma, shopping de Turvo, nos shopping de todas as cidades, por que têm brinquedos nos shopping de Criciúma, de Araranguá, de Turvo, tudo isso e queria do shopping uma Baby Alive a que passa na propaganda".

Nesse sentido, Esperança (2013, p. 95) reflete:

[...] isto é, a vida conduzida no ambiente da sociedade, estas são articulações entre cultural infantil e consumo, enfatizando que, num ambiente social centrado em buscas consumistas e em empreendimentos individualistas, o fascínio pelas

exibida no horário ás 21h30min.

${ }^{5}$ Cúmplices de um resgate é uma telenovela infantil brasileira produzida pelo Sistema Brasileiro de Televisão (SBT) e exibida no horário ás 20h30min.

Saberes Pedagógicos, Criciúma, v. 1, n²2, julho/dezembro 2017.- Curso de Pedagogia- UNESC 


\section{SABERES PEDAGÓGICOS}

Revista do Curso de Graduação de Pedagogia - Unesc

mercadorias e o impulso compulsivo e vicioso de comprar tornam-se as principais virtudes a serem promovidas e cultivadas nas crianças desde seu nascimento.

A autora ainda comenta que em todos os lugares comerciais há produtos voltados para o público infantil, embora alguns estabelecimentos tenham poucos produtos, assim as crianças são levadas a serem consumidoras cada vez mais cedo.

\subsection{Algumas considerações}

Para entendermos melhor a parceria dos pais junto a escola na esfera das escolhas de seus filhos quanto a moda e brinquedos vale ressaltar que das seis crianças, quatro delas direcionaram os seus pedidos, seus gostos ou até mesmo seus sentimentos a figura materna mãe -, isto explica por que em muitos lares a mãe é a figura central da família, mas isto não exime a responsabilidade do pai diante dos acontecimentos da mídia.

No entanto compreendendo que educar não é dar tudo o que o filho ou a filha pedem. Percebe-se que os adultos que convivem com as crianças, sobretudo os pais confundem o ato de educar com "faça o que quer." Nas imagens produzidas pelas crianças em desenhos é possível ver que o apelo da mídia é muito forte e constante, levando a identificar que estamos no "mundo das telas" (CRIANÇA, 2007), um mundo que nos oferece "tudo de bom" e o "de melhor", deixando transparecer que só se é feliz se tiver a "marca" dos seus "heróis e princesas." Olhando por esses viés pode-se inferir que as crianças no mundo do mercado, não são vistas como uma criança são vistas como meras consumidoras. Elas ditam o que querem, convencem os pais e assim recebem os produtos desejados. $\mathrm{Na}$ sociedade onde vivemos reações do tipo "eu vi e eu quero..., eu quero igual aquele..., ou minha mãe disse que vai comprar uma bota da Frozen daquelas que onde pisa congela tudo." Presentes na fala de Elza são comuns.

Falas deste tipo tornaram-se cada vez mais presentes nos dias de hoje, visto que para o mercado, sendo as crianças alvo das vendas é necessário procurar a adaptar a cultura da criança, e da infância. Sobre esta constatação Sarmento adverte que:

Esta indústria cultural infantil, cada vez mais poderosa, tem, para além das implicações econômicas uma dimensão sócio-cultuaral: tem produzido, como que

Saberes Pedagógicos, Criciúma, v. 1, n² , julho/dezembro 2017.- Curso de Pedagogia- UNESC 


\section{SABERES PEDAGÓGICOS}

Revista do Curso de Graduação de Pedagogia - Unesc

num encerramento, do círculo da negatividade, a ideia de que as crianças vivem, definitivamente, um processo de adultização precose e reversível e por consequência, habitam a idade da não-infância. (SARMENTO, 2000, p.145).

Neste contexto são muito preocupantes os desafios nos tempos modernos, por que revelam os dilemas e os problemas de ser criança e como ter infância. Por isso, que neste vale ressaltar que "a infância está em processo de mudança, mas mantém-se como categoria social, com características próprias.” (SARMENTO, 2004, p. 10). Estas características próprias como aponta o autor, são atributos que se transformam de acordo com as transformações da sociedade.

\section{CONCLUSÃO}

Neste artigo procurei trazer nas vozes das crianças participantes da pesquisa suas relações com a moda infantil e os brinquedos diante das ofertas de produtos midiáticos, percebendo também suas expressões ao verem e tocarem tais objetos. No decorrer deste artigo foram produzidas reflexões sobre as crianças e suas infâncias atribuindo-lhe o título de sujeito, elas passam a ter voz no seio familiar, podendo fazer suas próprias escolhas. Deste modo a mídia percebendo que as crianças podem influenciar nas escolhas e nas compras, passa a ter um olhar mais refinado e direcionado às crianças, percebem que não só podem ser consumidores potenciais, como também "consumidores efetivos" como coloca Esperança (2013).

Esse estudo procurou mostrar que desde cedo as crianças são alvos do marketing e da propaganda, pois acreditam que os apelos comerciais veiculados influenciam na vivência da infância, uniformizando sua maneira de vestir, brincar, de ter infância e ser criança. Portanto, na pesquisa constatei também muitos aspectos relevantes na influência da moda infantil preferidas mais usadas pelas crianças, o que elas mais consomem na relação de suas preferências por alguns tipos de vestes ou adornos, seus gostos, seus comportamentos, atitudes, expressões corporais, diante de tal objeto desejado. Direcionando para o campo escolar e em especial aos professores e professoras é importante que os mesmos tenham conhecimento sobre o mundo mediado com o marketing e propagandas, quais, onde, o que, e

Saberes Pedagógicos, Criciúma, v. 1, n², julho/dezembro 2017.- Curso de Pedagogia- UNESC 
Revista do Curso de Graduação de Pedagogia - Unesc

como consomem. É preciso que os professores estejam cientes desta realidade e, como poderiam trabalhar está questão, até porque eles convivem diretamente com as crianças.

Outra questão a discutir é sobre o comportamento dos pais ou responsáveis pelas crianças, percebe-se que muito deles se ocupam em agradar os filhos na compra de objetos de marca. Observa-se que os pais também são adeptos deste fato, pela simples questão de contribuir com o consumo, fazendo o desejo do filho, ou por tentarem suprir alguma ausência.

Portanto nestas vivências ofertadas pela mídia, à escola assim como a família é de extrema importância na construção dos valores, no que diz respeito ao que vale a pena ser consumido, compreendendo que depende da cultura, classe social, gênero e faixa etária, ou seja, nem todos consomem do mesmo modo.

\section{REFERÊNCIAS:}

ARIES, Philippe. L'Enfant et la Viefamílialesous I' Ancien Règime .. Tradução de. FLAKSMAN, Dora. História social da criança e da família. 2. Ed. Rio de Janeiro: JC, 1978.

BRASIL. Estatuto da Criança e do Adolescente. Brasília Casa Civil, 1990. Disponível em: http://goo.gl/1r8AvF. Acesso em: 03 de outubro de 2016.

BRASIL. Ministério da Educação Básica. Diretrizes curriculares nacionais para a educação infantil / Secretaria de Educação Básica. - Brasília: MEC, SEB, 2010, p. 12.

CRIANÇA, a alma do negócio. Produções Maria Farinha, 2007. Produção executiva: Marcos Nisti. Direção: Estela Renner. Disponível em: http://goo.gl/kqjk8t. Acesso: 15 de agosto de 2016.

CRUZ, Silvia Helena Vieira (org). A criança fala: a escuta de crianças em pesquisas. São Paulo: Cortez, 2008.

ESPERANÇA, Joice Araújo. Ser criança na sociedade de consumidores: outros tempos, outras infâncias. 2013 201f. Tese (Doutora em Educação ambiental) - Universidade Federal do Rio Grande do Sul. Rio Grande do Sul. Disponível em: http://0000010491.pdf. Acesso em: 12 de setembro de 2016.

FERNANDES, Rogério e KUHLMANN, Moisés Jr. Sobre a história da infância. In: FARIA, Luciano Mendes Filho (org.). A Infância e sua educação: Materiais, práticas e representações. Belo Horizonte: Autentica, 2004. P.15-34. (Sobre a história da infância 
FERREIRA, Aurélio Buarque de Holanda. Minidicionário da língua portuguesa. 3.ed. Rio de Janeiro: Nova Fronteira, 1993.

KUHLMANN, Moisés Jr. Infância e Educação Infantil: uma abordagem histórica. Porto Alegre: Mediação, 1998.

LEITE, Maria Isabel. Espaços de narrativa: onde o eu e o outro marcam encontro. In: CRUZ, Silvia Helena Vieira. (Org.) A criança fala: a escuta de crianças em pesquisas. São Paulo: Cortez, 2008, p. $43-157$.

POSTMAN, Neil. O desaparecimento da infância. Rio de Janeiro: Graphia, 1999.

QUEIROZ, Gregório J. Pereira de. A música compõe o Homem, o Homem compõe a música. São Paulo: Cultrix, 2000. 184 p.

ROCHA, Eloisa Acires Candal. Por que ouvir as crianças? Algumas questões para o debate científico multidisciplinar. In: CRUZ, Silvia Helena Vieira (Org.) A criança fala: a escuta de crianças em pesquisas. São Paulo: Cortez, 2008, p. 45-51.

SARMENTO, Manuel Jacinto (2000), Sociologia da Infância: Correntes, problemáticas e Controvérsias. Sociedade e Cultura, Cadernos do Noroeste, 13(2), pp. 145-164.

SARMENTO, Manuel Jacinto. Imaginário e cultura da infância. Pelotas: Caderno de Educação. Jul/ dez, 2003.

SARMENTO, Manuel Jacinto (2004). "As Culturas da Infância nas Encruzilhadas da 2a Modernidade” In: M. J. SARMENTO e A B. Cerisara (org), Crianças e Miúdos.

Perspectivas Sócio-Pedagógicas da Infância e Educação. Porto: Asa.

SARMENTO, Manoel Jacinto (2006). Infância, diversidade e expressão simbólica.

Disponível em: goo.gl/Dx5gVF. Acesso em: 18 de setembro de 2016. 